\title{
Editorial: Anticipation and change
}

\section{Lauri Linask, ${ }^{1}$ Inesa Sahakyan, ${ }^{2}$ Aleksei Semenenko ${ }^{3}$}

Work on this special issue started in 2019 under the auspices of the Nordic Association for Semiotic Studies (NASS). This organization, which serves to bring together the semiotics communities of the European countries in the Nordic and the Baltic regions - Denmark, Estonia, Finland, Iceland, Latvia, Lithuania, Norway, and Sweden - held its 11th international conference at the University of Stavanger, Norway, on 13-15 June 2019, with the theme of the same name as this issue, "Anticipation and Change".

Although the purpose of NASS as an organization has been to endorse and facilitate contacts, cooperation, and development of research collaboration and projects between its member countries, the conference at the University of Stavanger had a far broader international scope. In fact, it brought together about 60 participants from all over Europe as well as the USA. These introductory notes set out to give a brief overview of NASS as an organization, of the Stavanger conference, and of the resulting issue of Sign Systems Studies, the oldest international semiotic periodical in the world.

NASS was founded in 1987 at a meeting of Nordic semioticians in Imatra, Finland. Its first series of conferences and week-long Nordic Research Courses took place in Odense, Denmark (1990), Lund, Sweden (1992), Trondheim, Norway (1994), Imatra, Finland (1996), Oslo, Norway (1998), and Copenhagen, Denmark (2000). It then fell into a period of hibernation for more than a decade until May 2011, when the 7th conference of NASS was organized in Lund, Sweden. The conference was a success and brought together many seminal scholars from all over the world. This revival was confirmed the following year by the 25 -year

\footnotetext{
School of Humanities, Tallinn University, Narva mnt 25, 10120 Tallinn, Estonia; e-mail: lauri.linask@tlu.ee.

2 Department of Applied Foreign Languages, UFR LE, Bâtiment Stendhal G, CS 40700, 38058 Grenoble Cedex 9, University of Grenoble Alpes, France; e-mail: inesa.sahakyan@univgrenoble-alpes.fr.

3 Language Studies, Umeå University, 90187 Umeå, Sweden; e-mail: aleksei.semenenko@ umu.se.
} 
anniversary symposium held in Imatra, Finland, as part of the 27th International Summer School for Semiotic and Structural Studies. A new constitution was adopted, with a new board consisting of two representatives from each member country. As a result of this new impetus, NASS has been regularly holding a series of biennial conferences - in Lund, Sweden (May 2011), Aarhus, Denmark (May 2013), Tartu, Estonia (August 2015) and Kaunas, Lithuania (June 2017). The latest meeting of NASS took place in Stavanger, Norway, in June 2019.

Over the years, NASS has grown and developed as an organization, increasing the number of its member countries, holding regular biennial conferences that circulate in various locations in the region, and experiencing growing representation and engagement within the international semiotic community (e.g., at the International Association for Semiotic Studies, IASS-AIS World Congresses in Kaunas, Lithuania, 2017 and Buenos Aires, Argentina, 2019). The organization takes pride in its practice of awarding grants and prizes for graduate students participating in its events. NASS has been promoting international collaboration and participation of researchers from far beyond the strictly Nordic and Baltic regions. Its website (http://nordicsemiotics.org) regularly publishes a newsletter containing research-related news, information on conferences, other events and publications, etc., from all over the world; it runs a popular Facebook page and a Twitter account, with the aim of popularizing semiotics among broader audiences.

The 11th conference of NASS "Anticipation and Change" took place in Stavanger, Norway, from 13 to 15 June, 2019. It was hosted by the University of Stavanger (UiS) and was co-sponsored by the Department of Social Studies (UiS) and "The Greenhouse: An environmental humanities initiative at the University of Stavanger". Its organiszers and chairs were Morten Tønnessen, the current president of NASS (since 2017) and one of the authors in this issue, and Daria Segal as the conference secretary.

Keynote speakers included Ingvil Hellstrand (University of Stavanger) who gave a talk entitled "Brave new world? Dystopia and social change in contemporary science fiction", Jon Kvist (Roskilde University) with "Recent welfare reforms: Development or dismantlement of the Nordic welfare model?”, Jaan Valsiner (Aalborg University) with "The little big sign-makers: What can be learned from children for general theory of sign mediation?", Nora Bateson (International Bateson Institute) speaking on "Unnamed senses, unscripted ethics, wide angle attention", and Eero Tarasti (University of Helsinki) with the talk "Being and transcendence - introduction to existential semiotics". The prize for the best graduate student presentation was awarded to Oscar Miyamoto (University of Tartu) for his paper "A travel to the future: Chronesthesia as anticipatory semiosis". 
The conference addressed a wide range of topics related to the notions of anticipation and change, such as the semiotics of child development and human development in general, social and societal change, cultural change, environmental change, ontogeny, and evolution. These broad areas were addressed from a semiotic perspective, drawing on the common ground between semiotics and other disciplines. The anticipatory aspect of the theme brought together scholars with presentations on future studies, the power of imagination and innovation, as well as learning and perception, expectation and prediction, foresight and preconception. The special issue of Sign Systems Studies is one of the results and outcomes of this large variety of research, first presented at the conference, then selected to be published in this issue.

This is not the first cooperation of NASS and Sign Systems Studies. In 2014, the journal also published a special issue under the title Sign Evolution on Multiple Time Scales [vol. 42(2/3)], guest edited by Kristian Tylén and Luis Emilio Bruni, which was a result of the eighth NASS conference held in Aarhus, Denmark, in 2013.

\section{Outline of the special issue}

The issue starts with Morten Tønnessen's article "Anticipating the societal transformation required to solve the environmental crisis in the 21 st century" that introduces an ecosemiotic approach to the two great challenges facing humanity in the 21 st century: solving an escalating environmental crisis, while safeguarding and further improving human living conditions. Tønnessen presents an ecosemiotic framework for the study of societal transformations and discusses political and other normative aspects of transformative semiotics in terms of umwelt theory and Deep Ecology. One of the questions tackled in the article is the direction of the human umwelt trajectory in the nearest future. Tønnessen outlines different plausible umwelt scenarios for human ecology in the 21st century - a business-asusual, an ecomodernist and a Deep Ecology scenario - and distinguishes between flexible and inflexible development paths.

Prisca Augustyn analyses the semiotic devices and mechanisms of shaping public opinion and beliefs. Her article "Solar energy discourse in the Sunshine State" is a case study of a 2016 Florida constitutional amendment. Augustyn explores multimodal discourse strategies put in place by utilities and energy corporations to promote constitutional amendments. Her semiotic analysis follows the voter from the billboards and flyers to the text on the ballot. Starting from Peirce's phenomenological categories, this critical analysis of the campaign reveals how the actual underlying goals of the amendment were shrouded in positive 
environmental and consumer protection narratives. George Lakoff's cognitive linguistics and Arran Stibbe's ecolinguistics support a more detailed analysis of the ballot text.

Juha Ojala examines how music affords exploration of social aspects of semiosis. In his article "Music as a non-arbitrary avenue for exploration of the social" he sets out to demonstrate how music signifies the social, beyond the fact that it is an inherently participatory social process. Drawing on the notions of 'hard facts' and 'soft facts', Ojala argues that in music, com-positions of sound constitute hard facts that stand for other facts, soft or hard, by being their metaphors. Shaping and reshaping music allows for safe playing and testing of acts and events, anticipating upcoming situations and changes through virtual situations of the world, social and non-social.

In her paper "Towards the semiotics of the future: From anticipation to premediation", Katre Pärn develops the ideas put forth by Nikolai Bernstein in the first half of the 20th century on how human beings anticipate, and thus model, various futures to come, both tracing the mechanisms of anticipation from its individual organismic activity to semiotically mediated collective forms analogous to Juri Lotman's cultural semiotic notion of collective memory. The paper views modelling of the future in terms of the semiotic resources and processes involved in the model-building.

Piotr Konderak's paper "Towards an integration of two aspects of semiosis" has as its goal to develop a uniform cognitive framework allowing for integration of semiotic and cognitive studies. Basing on Rowlands' idea of the Amalgamated Mind, the Semiotic Hierarchy framework (Jordan Zlatev) and Peircean semiotics, Konderak analyses meaning-making activity as shaped by both 'external' (to a semiotic system) as well as 'internal' factors. On the one hand, according to the '4e approaches' (enactive, embodied, embedded, extended), meaning-making processes are constituted by (and not just dependent on) environmental and bodily factors and the dynamicity of semiosis can be accounted for in terms of an experiencing, embodied subject (agent) enacting her/his/its own domain of meaningful phenomena. On the other hand, in the Peircean view, semiosis is a result of the very nature of a sign and a sign system, and the dynamicity of semiosis has primarily 'internal' sources and stems from the unavoidable fallibility of interpretation and synechism of signs. The paper offers a uniform cognitive framework with the purpose to unify these two aspects of semiosis.

Inesa Sahakyan sets out to analyse innovation within the framework of Peircean semiotics, in particular in the light of Peirce's conception of inference, in her paper titled "Metaphor, induction and innovation: Getting outside the box". The paper reviews the Peircean types of inferences, arguing that while creativity 
and innovation are often analysed in terms of abduction, a parallel can be drawn between modes of inferences and types of hypoicons, suggesting that what makes innovation possible is the metaphoric reasoning underlying induction.

In his paper "Trajectories of anticipation: Preconceptuality and the task of reading habit" Sebastian Feil compares Peirce's notion of habit with Gadamer's notion of prejudice, Foucault's notions of the preconceptual and the dispositif, and Hans Blumenberg's conception of metaphor. Feil argues that, on the one hand, these somewhat similar approaches help to bring out the aspects of historicity and rule-association already set within Peirce's notion of habit. On the other hand, the comparison helps to underscore the relevance of habit in conceptualization, as a major part of a concept's coordinative power lies with the habits associated with the concept.

In her article "Narratives and the semiotic freedom of children", Sara Lenninger explores how adults' habits-of-thought and their understanding of children's stories shape the way adults interpret children's participation in conversations. In the light of the requests on children's rights that follow from the Convention of the Rights of the Child (CRC), this paper stresses the relevance of authorities having semiotically informed knowledge on children's meaning-making in conversations with adults. Drawing on sociological studies which have highlighted the importance of adopting the child's perspective in judging matters that concern her, this study suggests that a narrow conceptualization of the sign can facilitate better observation of different levels of meaning in adults' and children's conversations.

Donna West brings together Peirce's and Vygotsky's approaches in her paper titled "The dialogic nature of double consciousness and double stimulation: Implications from Peirce and Vygotsky". She argues that abductive reasoning is informed by internal/external dialogue in what Peirce deemed as double consciousness, and outlines a mental give-and-take forum in which novel meanings/ effects are particularly highlighted and noticed. She proposes further that the dialogic nature of these processes can be studied by experimental methodologies suggested by Vygotsky's 'double stimulation' paradigms that bring forth decisionmaking processes with the introduction of conflicts of motive in the experimental setup.

The articles making up this special issue explore the notions of anticipation and change as they appear today at the intersection of society's needs, demands and challenges. The authors endeavour to demonstrate and foreground the potential that semiotics bears in throwing light on such complex issues. Our sincere thanks are due to all the contributors and to the editorial team of Sign Systems Studies for the possibility of making this work available in the journal. 